\title{
STATE-OF-THE-ART OF 3D NATIONAL MAPPING IN 2016
}

\author{
Jantien Stoter ${ }^{\mathrm{a}, \mathrm{b}}$, Bruno Vallet ${ }^{\mathrm{c}}$, Thomas Lithen ${ }^{\mathrm{d}}$, Maria Pla ${ }^{\mathrm{e}}$, Piotr Wozniak ${ }^{\mathrm{f}}$, Tobias Kellenberger ${ }^{\mathrm{g}}$, Andre Streilein ${ }^{\mathrm{g}}$, Risto Ilves ${ }^{\mathrm{h}}$, \\ Hugo Ledoux ${ }^{b}$ \\ ${ }^{a}$ Kadaster, Apeldoorn, Jantien.stoter@kadaster.nl \\ b3D Geoinformation, Delft University of Technology, Delft, The Netherlands, \{H.Ledoux|J.e.stoter\}@tudelft.nl \\ ${ }^{c}$ IGN, France, bruno.vallet@ign.fr \\ ${ }^{\mathrm{d}}$ Lantmateriet Sweden, Thomas.Lithen@1m.se \\ ${ }^{\mathrm{e}} \mathrm{ICGC}$, Catalonia, maria.pla@icgc.cat \\ fGugik, Poland, piotr.wozniak@gugik.gov.pl \\ g swisstopo, Tobias.Kellenberger@swisstopo.ch, Andre.Streilein@swisstopo.ch \\ ${ }^{\mathrm{h}} \mathrm{NLS}$, Finland, risto.ilves@maanmittauslaitos.fi
}

Special session - SpS 12 - EuroSDR: Innovative technologies and methodologies for NMCAs

KEY WORDS: 2.5D and 3D mapping, National Mapping Agencies, EuroSDR 3D Special Interest Group

\begin{abstract}
:
Techniques for 3D mapping are maturing. At the same time the need for 3D data is increasing. This has pushed national (and regional) mapping agencies (NMAs) to consider extending their traditional task of providing topographic data into the third dimension. To show how research results in 3D mapping obtained over the past twenty years have been adopted by practice, this paper presents the ongoing work on 3D mapping within seven NMAs, all member of the 3D Special Interest Group of European Spatial Data Research (EuroSDR). The paper shows that some NMAs are still in the initial (experimental) phase of 3D mapping, while others have already built solid databases to maintain $2.5 \mathrm{D}$ and $3 \mathrm{D}$ topographic data covering their whole country.
\end{abstract}

\section{INTRODUCTION}

Techniques for collecting, reconstructing and maintaining $3 \mathrm{D}$ information have matured and many applications make use of 3D data ranging from flooding and noise simulations to energy and urban heat island calculation. Consequently, there is an increasing need for up-to-date, countrywide 3D data. Several National and Regional Mapping Agencies (NMAs) in Europe are making the step from $2 \mathrm{D}$ to $3 \mathrm{D}$ mapping to produce such data or are considering to make this step.

To join experiences and pursue the research agenda for $3 \mathrm{D}$ mapping, twelve European National Mapping Agencies have organised themselves in a 3D Special Interest Group within the organisation "European Spatial Data Research" (i.e. EuroSDR 3D SIG). This paper summarises the progresses on 3D national mapping made by a selection of these NMAs and the remaining issues that they face. It updates the paper that this group wrote in 2014 (Stoter et al, 2014). More specifically the paper describes the following recent developments:

- Section 2: ICGC (Catalonia) experiences on the generation of $3 \mathrm{D}$ raster models derived from the oblique camera and the improvement of the vector model for urban data to accommodate richer information related to $3 \mathrm{D}$ city modelling.

- Section 3: The Swedish experiences on a common national $3 \mathrm{D}$ visualisation environment for $3 \mathrm{D}$ geodata from the NMA, maritime administration, geological surveys and municipalities.

- Section 4: Activities by GUGiK (Poland) on setting up a 3D building database for the whole country and their plans to make it available for customers before end of 2018 .

- Section 5: 3D mobile mapping at IGN France: recent developments resulted in a production vehicle and many developed tools to exploit such data in the IGN France research Lab.

- Section 6: 3D mapping at national level in Finland.

- Section 7: 3D mapping at swisstopo, Switzerland.

- $\quad$ Section 8: 3D national mapping at Kadaster NL.
The paper ends with concluding remarks in Section 9.

\section{3D MAPPING AT ICGC}

The Institut Cartogràfic i Geològic de Catalunya (ICGC) is the regional mapping agency of the Government of Catalonia. From its creation in late 1982, the ICGC activities in the cartographic production have been focused continuously in the improvement of the production workflows.

The production of topographic data includes the scales 1:1.000 (CT-1M) in urban areas, and 1:5.000 (BT-5M) and 1:25.000 (BT-25M) covering all the country. The data are collected mainly using photogrammetric systems, completed in urban areas by data surveyed on the field, and updated in a period of 5 years and more frequently if there are important changes in infrastructures. Data are stored in an ORACLE database using 2.5D data models, where each vertex is defined by $\mathrm{X}, \mathrm{Y}$ and $\mathrm{Z}$ coordinates. Data at 1:1.000 and 1:5.000 scales include a rich collection of altimetric data, including break lines, that allows to derive a digital terrain model (DTM) and a digital surface model (DSM). These elevation models are widely used in orthophoto rectification and in the contour and shadow relief generation ensuring a complete coherence between planimetric and altimetric information.

LoD1 city models are automatically derived from 1:1.000 scale and 1:5.000. Since 2002 LiDAR systems are an additional source to obtain elevation data, with a full coverage of Catalonia available with 0,5 points $/ \mathrm{m} 2$, and a partial coverage at higher densities along the coast and over other specific areas. In 2014 an oblique camera was bought to obtain more accurate 3D information on urban areas. The ICGC products, including data, metadata and specifications, are distributed free-of-charge according the Creative Commons licence CC-BY.

Current tasks in 3D work focus on the improvement of the CT$1 \mathrm{M}$ data to accommodate richer information related to LoD2 city modelling, in the generation of $3 \mathrm{D}$ raster models derived from images obtained with the new oblique camera and 3D products derived from LiDAR data, in the dissemination of 3D data and to find new applications of its enormous potential. 


\subsection{Improvement of the topographic model at 1:1.000 scale}

The first line of the 3D work in progress is focused in the enrichment of the CT-1M data model, adding detail of the roofs for obtaining LoD2 city models (see Figure 1) and the topographic information under bridges and other constructions. In the current topographic model, buildings include flat polygons derived from linear boundaries, where each vertex of the boundary is collected in the coordinates $\mathrm{X}, \mathrm{Y}, \mathrm{Z}$ at the real height, and a centroid to indicate the highest or the more significant value of the roof. In the new model it is planned to collect the roofs with all the 3D details, including the overhangs. After some tests on Tridicon software for obtaining inclined roofs automatically, based on oblique image correlation and building boundaries, the results are promising although manual tasks will be required to refine them. Main limitations of Tridicon software are related to its pattern recognition method using predefined types of buildings, which in most cases are not well adapted to the irregular buildings and constructions of the territory.
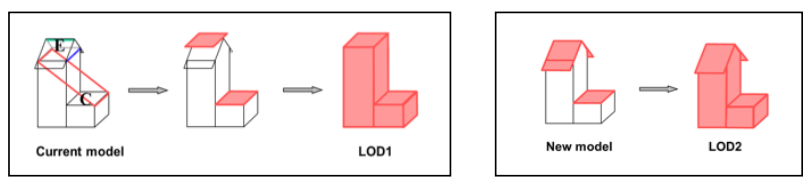

Figure 1 Building data capture in the current and in the new models

Data model improvement will also consider transportation networks. In the current model the network is collected by linear elements. In bridges, all the required information is collected to model the terrain under the bridge (DTM) and to model the upper construction (DSM). In the new model polygons will added on top of the bridges to facilitate the classification and the exploitation of the topographic information under them (see Figure 2).
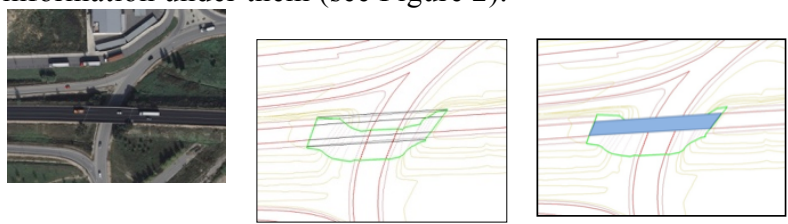

Figure 2 Bridges data capture in the current (left) and in the new (right) models

As it is in use in the BT-5M and the BT-25M databases, this model will include for each feature instance an identifier unique and persistent along its whole life-cycle, and its characterization by temporal, metadata, and thematic attributes. The life-cycle information will describe temporal characteristics to make feature versioning possible; the metadata attributes will contain the information related to quality and lineage (survey, stereoplotting, field collection, external databases or other); and, finally, features will have a set of thematic attributes to characterize them. The availability of identifiers and life-cycle attributes will facilitate the updating processes, will allow the distribution to the users of incremental updates and the relationships with related databases (addresses, map names, etc) to facilitate, for example, the propagation of changes. The design of the new model will also guaranty the compatibility between the concepts existing in the ICGC data model if they exist in other models and standards, as CityGML and INSPIRE.

Main issues in this work are the identification of real customer needs and the achievement of a balance between the complexity of the model and the cost to be maintained during the updating processes. Regarding to the customers need: although the model is designed as a corporative task involving producers and users of the data of different government administrations being mainly municipalities, at the moment the main use is still visualization. Related to complexity and cost, the ICGC approach is to enrich the model by steps, avoiding features, attributes and relationships existing in the standards but not to be used in the next future, for example, the new ICGC model probably will not yet include polygons of the surfaces of roads and streets.

\subsection{D products from oblique images and LiDAR data}

Additional to the $3 \mathrm{D}$ vector data, ICGC is providing also $3 \mathrm{D}$ products based on raster data collected using the recently acquired Leica RCD30 Oblique Camera and, since 2002, the LiDAR systems.

One of the main uses of the oblique images is the generation of the textures to the LoD2 buildings of the new topographic model and the generation of 3D raster models. Current vector LoD1 data is provided without textures. Although some pilot projects have been performed to add textures to the model using aerial or terrestrial images, the results have been poor or too costly. Multiple views from the oblique camera images will allow the addition of the textures to the LoD2 buildings of the new topographic model, solving the previous limitations (Figure 3 and Figure 4).
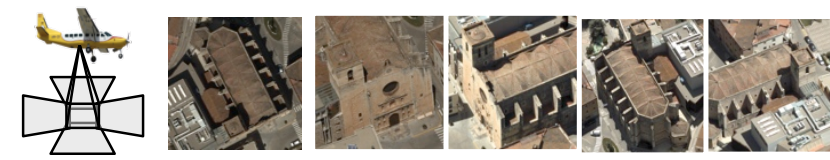

Figure 3 Multiple views collected by the oblique camera
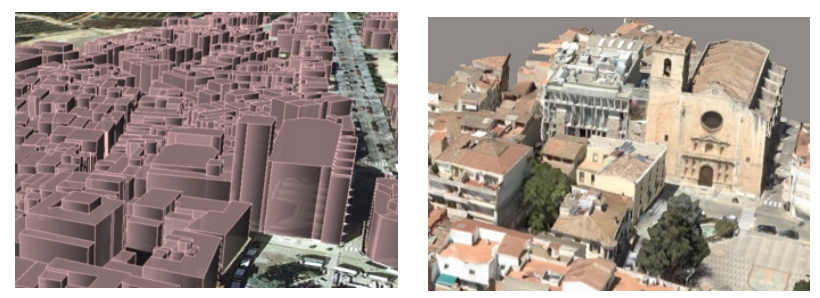

Figure 4 Current LoD1 model without textures and the LoD2 model texturized using oblique images

Because the new topographic model is yet in design phase, and it will require some time before to get it implemented in the production environments and to have a significant coverage of data available, it has been considered that the production of 3D raster models based on hyperrealistic textured triangulations can provide a 3D product very useful for most visualization applications (Figure 5).
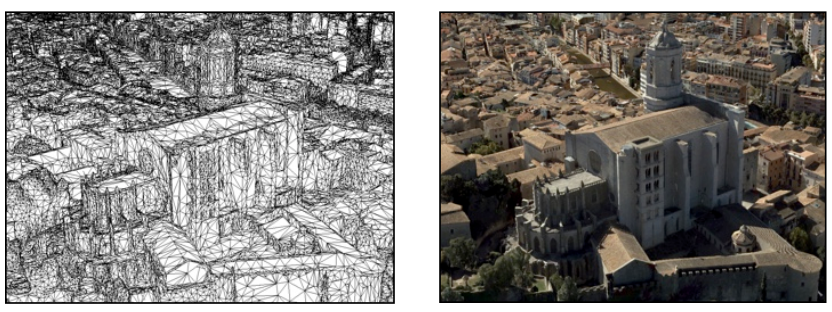

Figure 5 Hyperrealistic textured triangulation from the oblique images 
ICGC is preparing a workflow to generate automatically this product, shortcoming the problems of the software provided together with the oblique camera, which is not robust enough to manage the huge volume of data required to generate the ICGC annual production.

First coverage of LiDAR data was collected between 2008 and 2011 at 0,5 points $/ \mathrm{m} 2$, and the main uses were related to flood analysis. Since 2008 regular flights have been collecting higher density LiDAR data, at 1 point $/ \mathrm{m} 2$ along the coast for monitoring the littoral changes and at 4 points $/ \mathrm{m} 2$ in populated areas for deriving urban applications, for example the analysis of the solar potential of the buildings (Figure 6).

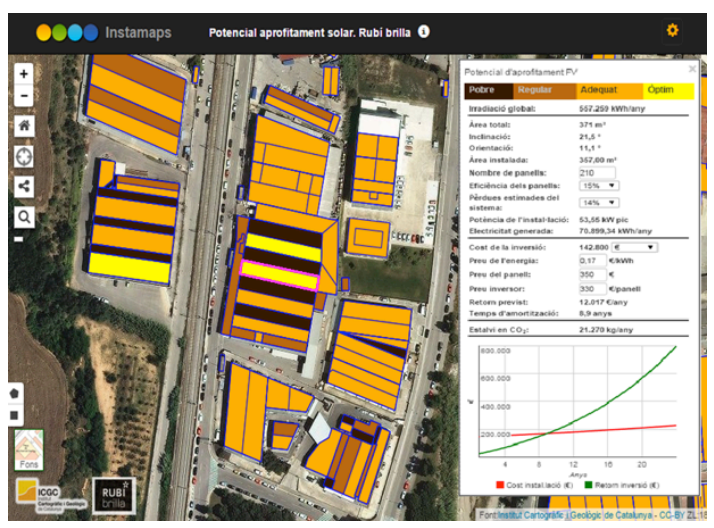

Figure 6 Application to provide the solar potential of buildings based on LiDAR data

\subsection{Dissemination of 3D data}

Nowadays ICGC data can be accessed through a portal, used through geoservices and downloaded in several vector formats, as SHAPE, DGN, DXF or KMZ, and also raster formats. LiDAR data are available in LAZ format. By the moment data is mainly used for $2 \mathrm{D}$ applications, and, although there is a huge potential of city model applications (urban planning, telecommunications, energy, environment, smart cities, simulations, etc.), visualization is the most common while the other ones are not yet enough developed.

For the visualization of $3 \mathrm{D}$ datasets, ICGC is currently studying a $3 \mathrm{D}$ viewer based in Cesium technology and the first prototypes are in test phases. The WebGL Cesium library allows the presentation of $3 \mathrm{D}$ graphics in web pages, and taking advantage of the acceleration provided by the user computer, achieves an excellent quality and speed from the web browser.

Finally, to facilitate and to spread the use of city models, an ongoing project analyses in depth the requirements related to the use of ICGC data for 3D city modelling in architecture projects, and an specific user profile is being implemented to provide ICGC data better adapted to this professional field. The plans for the next future are to analyse in depth other fields.

\section{THE SWEDISH EXPERIENCES ON A COMMON NATIONAL 3D VISUALISATION}

Lantmateriet - the Swedish mapping, cadaster and land registration authority - was in 2013 commissioned by the Government to investigate the possibilities for the provision of mapping and image information in 3D. The user needs assessment conducted during the investigation found that there is growing demand for geodata in $3 \mathrm{D}$ to do better visualizations, analyzes and plans in areas such as urban and infrastructure planning as well as in climate adaptation work.

Existing data themes in 2D should over time be provided and displayed in 3D. The aim should be that existing data themes from Lantmateriet along with data themes from other authorities gradually should build up a common 3D landscape model that meet society's basic needs. As part of this work a common framework for 3D should be developed in collaboration with other authorities as well as a test platform for the visualization of spatial data in $3 \mathrm{D}$.

Work has begun with the Geological Survey of Sweden, the Swedish Maritime Administration, the Swedish Transport Administration, Swedish forest agency and the municipalities. Experience to date shows that (see Figure 7):

1. The existing elevation models in $2.5 \mathrm{D}$ from different agencies can be displayed in a common application after some editing and knowledge on quality. The models tested together are DTM, DSM, a seabed model and a bedrock model. It is possible to set up these height models as WCS services at the responsible authority for real-time delivery.

2. It is possible to use existing 2D WMS services at each responsible authority to drape on the different height models for $2.5 \mathrm{D}$ in real-time. Water, transportation, land cover and orthoimagery is draped on the DTM. Hill shading on the DTM and seabed. Forest polygons on the DSM. Soil and groundwater on the bedrock.

3. There is currently no good standard services to provide 3D objects for visualization like buildings, power lines, wind turbines, boreholes and other artificial 3D objects that are above and below the ground surface. These objects are at the moment stored and delivered by the application provider.

Lantmateriet collects buildings in-house for rural areas and in cooperation with municipalities for urban areas. The buildings are measured in-house in $2.5 \mathrm{D}$ with photogrammetry and roof edges are stored in a $2.5 \mathrm{D}$ database. The municipalities use photogrammetry or terrestrial measurements to collect in different $2 \mathrm{D}$ or $3 \mathrm{D}$ models. There is a collaborative project between Lantmäteriet and the Swedish municipalities regarding a new information model for $3 \mathrm{D}$ building to be used for national data exchange. The new model is based on the old model, CityGML LoD0-3 and INSPIRE.

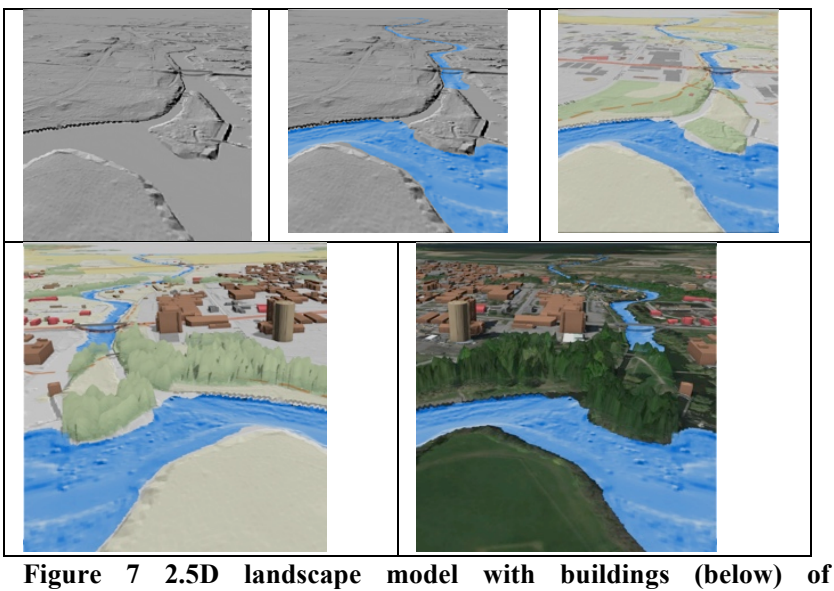
Lantmateriet

\section{3D MAPPING AT GUGIK, PLAND}

On November 19th 2015, the Head Office of Geodesy and Cartography (GUGiK) has begun implementation of the CAPAP project (Public Administration Center for Spatial Analysis) where one of main tasks is to set up 3D building models database for the entire country in LoD2 CityGML 
standard together with procedures and tools to keep it updated. It is planned to use ALS (4-12 points $/ \mathrm{m} 2$ ) and 2D outlines of buildings from Topographic Objects Database as a main data source. Whole process of production is going to be outsourced, quality control will be conducted mainly by external contractor however final verification will take place in-house.

Terms of Reference are being prepared in close cooperation with defined customers. In 2014 GUGiK conducted a survey regarding customers needs and received feedback from 650 public and private organizations followed by dedicated meetings with further 92 organizations in a second step of consultations.

First 3D data will be available in second half of 2017 and whole dataset will be ready for use before end of 2018. GUGIK considers to distribute 3D database as an open dataset which will potentially strengthen application of data and economic grow in sector of geo-bussines in Poland. In addition to $3 \mathrm{D}$ database it is planned in CAPAP initiative to implement analytical environment for customers facilitating utilization of 3D data as an extension of geoportal.gov.pl environment. To meet customers expectations GUGiK is in testing procedure of 3D web viewer with analytical functionalities (see Figure 8).

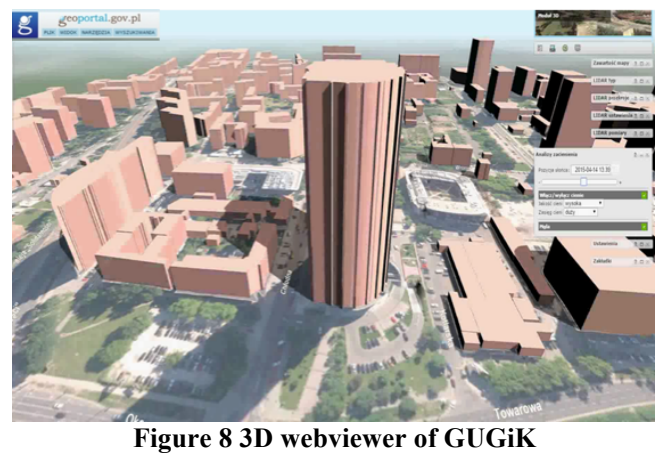

\section{3D MOBILE MAPPING AT IGN FRANCE}

Mobile mapping consists in the dynamic numeration of the environment at very high spatial resolution from a mobile terrestrial platform. Mobile mapping systems are of utmost interest in the context of fine scale 3D mapping of urban areas and have been a fast growing trend for the past decade. This has several reasons. At first the resolution of airborne sensors has reached its limits, so the only possible improvement is getting closer to the scene. One possibility is with UAVs (that have also known a great boost recently), the other is with ground based platform. While fixed platforms are extremely limited in productivity, mobile mapping is the only ground alternative allowing for the coverage of an entire city in reasonable time. Another reasons for the increase interest in mobile mapping is that both the storage size capabilities and processing power keep growing. An increase in spatial data resolution implies a similar increase in data size. That aspect is all the more visible in the rise of a strong international BigData community.

Because of that trend, specific sensors (image, LiDAR, georeferencing) have also emerged, favoring the growth of mobile mapping. Importantly, the Google StreetView web service has much popularized mobile mapping (Anguelov et al., 2010). There is now an abundance of private mobile mapping operators (Here, Cyclomedia, StreetMapper from 3DLaserMapping, TopCon, Apple) often equipped with fully packaged systems (Optech, RIEGL VMX-450, Trimble MX8, Siteco). In parallel, research initiatives have seen the emergence of more and more precise systems: VISAT (ElSheimy, 1996), GPSVan (Grejner-Brzezinska, 1996), Lara3D
(Goulette et al., 2006), Roamer (Kukko et al., 2007), Photobus (Gontran et al., 2007), RoadScanner (Gandolfi et al., 2008), Stéréropolis (Paparoditis et al., 2012), or the Kitti initiative (Geiger et al., 2012).

The main challenge of mobile mapping is that of integrating and synchronizing image, LiDAR and georeferencing systems from the mechanical, electrical and software point of view so as to provide images and point clouds precisely georeferenced in a geographical reference system. Its main challenges can be divided into:

- Quality of the georeferencing: because of the high data resolution, many applications also call for a very accurate absolute geo-positioning (below $10 \mathrm{~cm}$ accuracy) which can only be obtained in good GPS visibility but not in dense urban cores. Some academic papers and commercial tools propose to use external data sources (tie points, 3D object locations) to improve the accuracy of the geo-positioning system in GPS denied environments.

- Scene complexity: compared to aerial acquisitions, the sensor is within the scene. That scene cannot be analysed in $2.5 \mathrm{D}$ but only with true $3 \mathrm{D}$ tools. This is quite a new paradigm in a geospatial community more used to $2 \mathrm{D}$ tools (orthophotos, digital elevation models, 2D vector data, ...)

- The specific acquisition geometry induces a much more anisotropic and variable resolution as in the aerial case where all objects lie at a rather similar distance from the sensor. Occlusions are also much more important.

- Dynamics: from the ground point of view, dynamic objects such as cars compose an important part of the scene and can hardly be neglected.

- Radiometric issues (reflexions, shadows, ...) in images are much more important and hard to correct.

- Data size (roughly 1Tbyte per day of acquisition) is very challenging for processing and visualization tools.

Despite these challenges, mobile mapping also offers huge improvements above traditional mapping techniques. Because of the proximity to the scene, mobile mapping unlocks numerous data production possibilities that are inaccessible to airborne acquisitions:

Facade analysis and reconstruction

- Precise road mapping (lanes separation, road/sidewalk separation, road marks/signs detection and reconstruction, road surface analysis and defects detection, gutters localization, ...)

- Urban objects detection and reconstruction (trees, urban furniture, poles, ...)

- Fine grained change detection

Some of these new products can have important applications for NMAs because related to national legislation, including building accessibility to the disabled and accessibility diagnostics and localization of underground networks. Other important applications for local collectivities include urban furniture inventory and degradation diagnostic (including road signs, road marks and road surface quality); car park usage monitoring; assessment of conformity of new constructions with the provided plans; mapping of vehicle and pedestrian flow. Finally, such data can support numerous services such as 3D monitoring from the office (based on a street view interface); mapping for autonomous navigation; and pedestrian itinerary computations and planning.

Most aspects listed above are still very prospective and are active fields of research. Therefore it is often hard for NMAs to define a position towards this field in constant developments. IGN France has chosen to maintain an expertise that initiated in its research laboratories by developing a production vehicle 
operated by a production service specialized in highly specific metrologic surveys (Figure 9). The aim is not only to develop such services but also to maintain an expertise, thus a legitimacy to advise local collectivities regarding mobile mapping, and to qualify the accuracy of private operators. Even if several large cities (including Paris) have been covered by mobile mapping acquisition, a nationwide coverage is not the target as the corresponding investment is too high. Mobile mapping is a promising technology that opens the door to numerous new applications of geospatial data, but the challenges it still faces makes it hard to deploy at large scale, and the amount and specificity of the collected data still calls for specific processing and interaction tools before being really exploitable by end users.

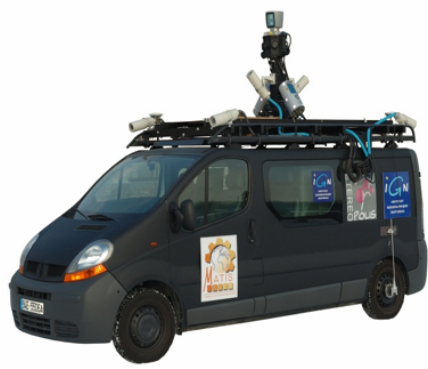

Figure 9 The mobile mapping system of IGN

\section{3D MAPPING AT NLS FINLAND}

The National Land Survey of Finland is responsible for national topographic data production in Finland. The current topographic data production is mostly based on aerial images and LiDAR data.

LiDAR data (minimum 0.5 points $/ \mathrm{m} 2$ ) is used for the DTM production. The final product is 2 meter grid. The feature collection is done by using stereo workstations. The height information for features is derived from the LiDAR based DTM i.e. current topographic data is $2.5 \mathrm{D}$.

Topographic data is available as open data from the portal https://tiedostopalvelu.maanmittauslaitos.fi/tp/kartta?lang=en

NLS has started a program to create a new National Topographic Database (NTDB) in beginning of 2015. First new version should be available in 2019 . One of the change is to support 3D data. Plan is to follow CityGML level of details (LoD) classification. The production is divided to three classes:

Class A: A city center, features are represented in LoD2 (or better if available from construction plans).

Class B: Other densely populated area or industrial area, features are represented in LoD2. Class B may also contain shore areas with recreational activities.

Class C: Other area, features are represented in LoD1 or LoD2. There is separate ISPRS paper with more detailed description of the NTDB.

\section{3D MAPPING AT SWISSTOPO, SWITZERLAND}

Referring to Switzerland from a land survey view means dealing with large elevation differences, pronounced terrain variations in the Alps, dense population and infrastructure in the mid lands and an increasing legal interest in claiming the air, the ground and the subterranean space. In 2008 the Swiss Federal Office of Topography (swisstopo) consequentially switched its land survey from a 2D map based approach to the straightforward 3D acquisition of the digital Swiss Topographic Landscape Model TLM (Schmassmann et al., 2010), see Figure 10 .

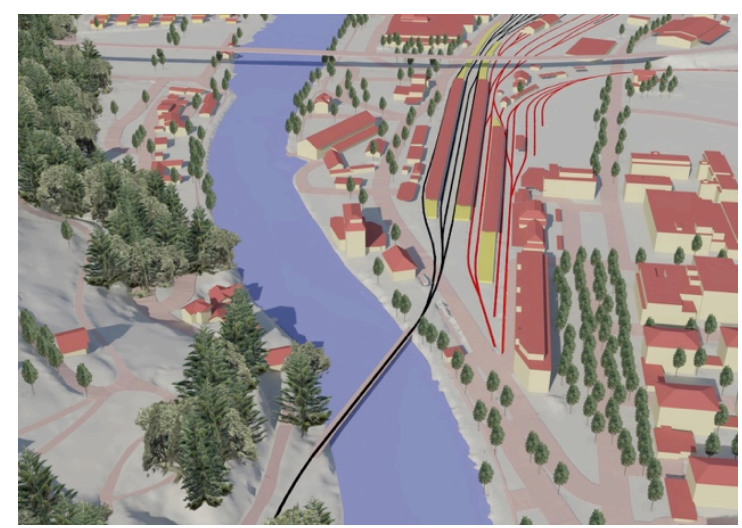

Figure 10 Representation of swissTLM3D elements near the City of Interlaken

The 3D database is the nationwide primary geometric reference with a precision of better than $1 \mathrm{~m}$ for all elements, captured either directly from aerial or satellite scanner data by photogrammetric techniques and/or data integration from authorities and organisations. Today most of the TLM elements are already built up and are subject to a regular update process, namely the digital terrain model swissALTI ${ }^{3 \mathrm{D}}$, roads and paths, the public transportation network, administrative boundaries swissBOUNDARIES ${ }^{3 \mathrm{D}}$, the name dataset swissNAMES ${ }^{3 \mathrm{D}}$, single prominent objects and lakes. The buildings swissBUILDINGS ${ }^{3 \mathrm{D}}$ are expected to be accomplished in 2018 followed by the land cover features, the areas of specific use and the hydrographic network in 2019 (swisstopo, 2016).

swissALTI ${ }^{3 \mathrm{D}}$ is a continuous terrain model in a $2 \mathrm{~m}$ mesh, based on LiDAR flights up to 2000 altitude and photogrammetrically extracted heights from aerial flights above. The model is updated in a regular circle using automatically extracted point clouds and manually measured break lines and contains even precise bathymetric information of the larger lakes. Swisstopo initiated a successive renewal of swissALTI ${ }^{3 \mathrm{D}}$ based on new LiDAR flights over the next seven years to end up with a surface model and a more accurate $1 \mathrm{~m}$ terrain model.

The roads and paths and the public transportation network, surveyed in true $3 \mathrm{D}$, are represented by network axes and attributes such as width, type, usage and more. The network is updated on a regular base. Arising discrepancies of the network altitude and the elevation data are revised immediately in the coupled data acquisition process of both, an approach valid for all the other TLM elements too. In contrast land cover, areas of specific interests and the hydrographic network are mapped in $2 \mathrm{D}$ and draped over the terrain model, resulting in $2.5 \mathrm{D}$ objects. swissBUILDINGS ${ }^{3 \mathrm{D}}$ is the $3 \mathrm{D}$ vector data set representing over 3 million buildings of Switzerland. The roofs are manually acquired in 3D from aerial digital images with a precision of better than $50 \mathrm{~cm}$ in all dimensions and complemented with attributes. The additional building elements (facades, footprints and roof overhangs) originate from automatic procedures (only where third party information is missing). Swisstopo fosters actually a big national effort which will allow for a simultaneous use of the geometric 3D data of swissBUIDINGS ${ }^{3 \mathrm{D}}$, the statistical information about households and living from national surveys and the legal and local information from the cantonal cadastral services: in the near future the swisstopo buildings and the cadastral building entities will refer both to the unique national statistical building identifier. 


\subsection{National 3D data viewer of Switzerland}

All public 2D governmental data of Switzerland is currently published on the federal geoportal (geo.admin.ch, 2016). In order to make better use of the 3D geo-data from swisstopo and to foster the dissemination of the data, swisstopo is pushing to expand the geoportal with 3D capabilities. Currently a preliminary viewer (see Figure 11) is available for the public, capable to show 2D information layers draped over an adapted terrain model (map.geo.admin.ch). swisstopo will start to add first 3D elements such as buildings, trees and structures over the coming month in order to comply with a true $3 \mathrm{D}$ viewer.

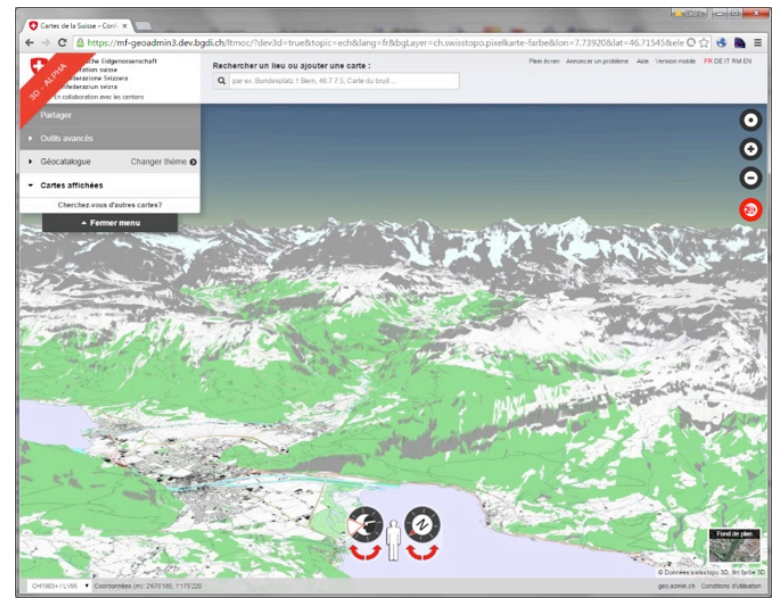

Figure 11 Preliminary 3D viewer on the federal geoportal of Switzerland

\section{3D NATIONAL MAPPING IN THE NETHERLANDS}

For several years, 3D mapping at the national level has got attention in The Netherlands. This is driven by a growing need for $3 \mathrm{D}$ data in applications such as noise calculation, flooding simulation, solar potential analysis, maintenance of dikes.

For that reason, the standard for large scale topography (IMGeo: Information Model Geography) is modelled as an Application Domain Extension of CityGML (Van den Brink et al, 2013a; 2013b). The standard was established in 2012. All organisations responsible for collecting large scale topography are obliged to provide such data according to the IMGeo standard from 2016 onwards. The 2D part is mandatory; the 3D part is optional.

In sequential research, we are investigating several issues to further develop towards a base 3D data provision.

\subsection{A national 3D data portal}

At first we are investigating how we can publish governmental 3D data (which can be 3D IMGeo, but also other 3D data like cables and pipelines, 3D data bout the geological underground etc) via a national portal. $2 \mathrm{D}$ data is being published via a national portal called Publieke Dienstverlening Op de Kaart (www.pdok.nl). In a testbed we will investigate with the community what the best options are for the interactive visualisation of $3 \mathrm{D}$ data via the Internet. Candidates for testing are Cesium, i3S (the open standard developed by Esri that contains an Indexed 3D Scene delivery format and the Scene Layer Package definition both encoded using JSON, Esri, 2016). We also plan to investigate the recently established 3D Portrayal Service from the Open Geospatial Consortium. The main challenge will be to publish both semantics and geometry at the same time and preferably directly from the database, without the conversion to other formats.

\subsection{D data reconstruction at national coverage}

A second item for research is the national wide $3 \mathrm{D}$ data reconstruction.

The extension of IMGeo towards 3D is the responsibility of individual organisations and thus not ready yet to provide a countrywide 3D data set. Therefore, in 2014 a countrywide 3D dataset has been generated from the object-oriented data at scale $1: 10 \mathrm{k}$ (the largest scale as maintained by the Netherlands' Kadaster) in combination with high-resolution airborne LiDAR data $\left(10+\right.$ points $/ \mathrm{m}^{2}$, available as open data). The $3 \mathrm{D}$ model was reconstructed in a consortium composed of Kadaster, the Delft University of Technology, the Twente University and the Free University of Amsterdam. For the 3D reconstruction the opensource tool was used developed by (Oude Elberink and Vosselman, 2009a; 2009b; Oude Elberink et al, 2013). The tools reconstruct a surface representation for each class in the $2 \mathrm{D}$ map by the integration of the $2 \mathrm{D}$ data and high resolution LiDAR data. For the volumetric objects (buildings and plant cover) the $3 \mathrm{D}$ reconstruction has until now been limited to LoD1 (block models). The reconstruction is driven by rules that prescribe how to process the LiDAR data, how to model specific object types, and how to connect neighbouring objects in 3D (Oude Elberink and Vosselman, 2009a; 2009b).

The lessons learnt from the reconstruction of 3D TOP10NL data are currently being used to develop a 3D reconstruction tool for 3D IMGeo (i.e. at more detailed level), based on 2D IMGeo data and height points (see Figure 12).

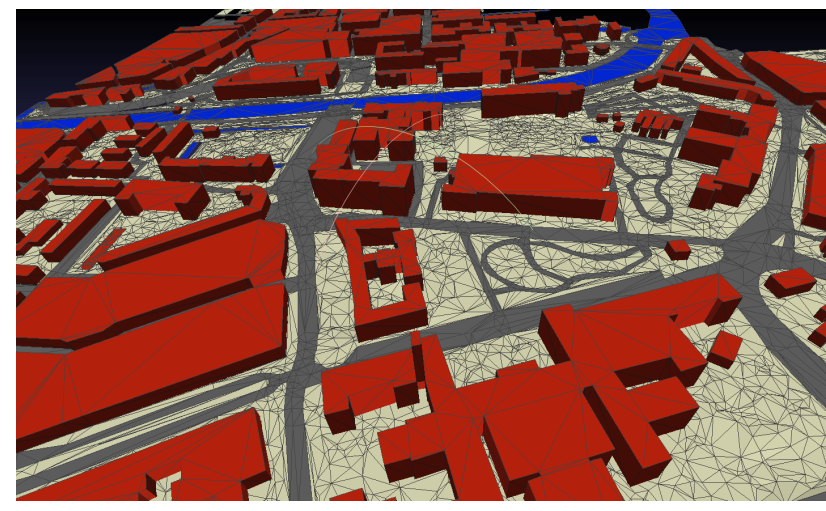

Figure 12 3D IMGeo data, automatically reconstructed from 2D IMGeo data and height points

Since the 2D source data set contains significantly more 2D features at higher detail, and since the original process was computational expensive (several fitting of planes with leastsquare adjustment), we are currently investigating simpler alternatives to assigning elevations to the features. Each feature, or part of a feature, would be "lifted" to 3D by using rules such as lowest within a given area (e.g. for water) or by using a certain percentile of all elevations points within an area. This will allow scaling the process to the whole country easily. For the buildings, we plan to decompose each footprint into parts whose elevation is similar. For this we will use the methodology of Commandeur (2012).

To use more updated height data than the LiDAR data (which is acquired every 5-6 years), the Netherlands' Kadaster are also investigating the use of height data obtained from dense image matching. 


\subsection{Create 3D-proof workflows for governmental organisations}

For several governmental workflows it is known that an integrated 3D approach will provide a more efficient way of working. However, this requires a change of work processes as well as additional agreements between different departments and organisations. Therefore, we will select one or two of such workflows and make an integrated $3 \mathrm{D}$ approach optionally possible. At first we look at workflows that already make full use of $3 \mathrm{D}$, but that could be more efficient with an integrated approach, such as carrying out a noise study or the process to apply for a building permit. Such cases will show the added value of working in 3D. In addition, they prepare governmental organisations to make the step towards 3D. Enabling a building permit to be submitted and checked in $3 \mathrm{D}$ requires that each step in that process supports such data. This workflow operates on the edge between BIM and GIS domains and detailed agreements are needed to make the workflow possible. In addition, an integrated approach to $3 \mathrm{D}$ noise studies, from the preparation of the 3D input data, and calculation of noise levels in $3 \mathrm{D}$ to dissemination and visualisation of the $3 \mathrm{D}$ output data of noise simulation studies, requires a change in the existing work processes. The cases will provide insight into what it takes to perform this work in $3 \mathrm{D}$, starting with countrywide $3 \mathrm{D}$ data, including agreements on the relevant 3D data ideally laid down in standards.

\subsection{D cadastre}

A related issue on national $3 \mathrm{D}$ mapping is $3 \mathrm{D}$ cadastre. A $3 \mathrm{D}$ cadastre should provide insight into complex ownership. In The Netherlands, like in many other countries, the ownership to real estate is established via 2D parcels. Multi-level ownership is established via limited real rights on the parcel such as easement, right of long lease and right of superficies. Although it is possible to legally establish 3D rights, until recently it was impossible to visualise these $3 \mathrm{D}$ rights. However, with the recently established acceptance of digital deeds, the registration of a 3D visualisation of multi-level rights in the form of a 3D PDF has become possible (Stoter et al, 2014). In March 2016, the Dutch Kadaster has registered the first 3D visualisation of the multi-level ownership of a building complex as a 3D PDF, see Figure 13.

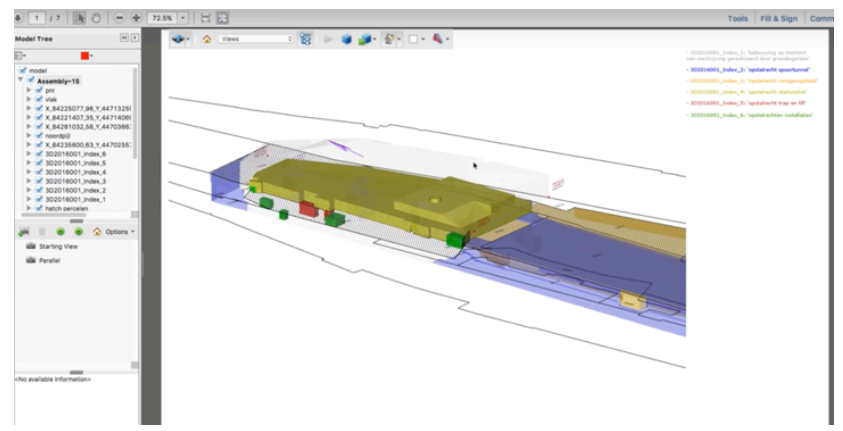

Figure 13 3D PDF, official document that visualises rights of multilevel ownership in 3D. It concerns the underground railway station in Delft.

The combined structure of the new city hall and the station of Delft, including the underground railway station and railway tunnel, as well as the underground bicycle parking place is the first to be registered in $3 \mathrm{D}$ in this way. The construction contains rights of three parties that come together in a compact amount of space: the municipality of Delft as owner of the land, NS Real Estate as holder of the station with shops and installations, lifts and stairs and ProRail / Railinfratrust as holder of the tunnel and the underground station.

For the 3D registration, the Kadaster has worked closely together with the city of Delft and the 3D Geoinformation group of TU Delft. The 3D visualisation was designed by Mecanoo Architects based on the BIM data generated in the design and construction phase. The notary Houthoff Buruma has issued the certificate for the deposit in the Land Registry.

Based on the experiences the registration of a 3D visualisation of complex ownership rights will be further developed and regulations may be adjusted accordingly.

\section{CONCLUSIONS AND FUTURE WORK}

In this paper we summarised recent developments on national 3D mapping for a selection of NMAs. It shows that NMAs are making significant steps to collect, maintain and provide $3 \mathrm{D}$ data to serve a wide variety of applications.

Despite the potentials of 3D, all NMAs observe an underuse of the $3 \mathrm{D}$ data they produce. To better understand the mismatch between the availability of 3D data and the use of it (beyond visualisation), the EuroSDR 3D SIG has started a research project on the identification of economic value of 3D geo data.

The project is funded through "crowdfunding": eleven National Mapping Agencies (NMAs) and EuroSDR as 12th partner each contribute financially. The results of the project will give the participating NMAs understanding in the business case of 3D data: In what applications does 3D give added value?; What are the required 3D data for these applications?; What are the costs and benefits to collect and maintain these 3D data nationwide? The project has started early 2016 and is expected to run for one year.

Another related activity is the development of common specifications for 3D mapping. The objective of this shared specification for 3D mapping is to define how objects in existing 2D map databases at NMAs could be represented geometrically in 3D. It builds on existing concepts like the Levels of Details, commonly used in CityGML and semantic data specifications of INSPIRE. These common specifications for 3D mapping will support joining 3D experiences and efforts in different countries. In addition they will enable to build on each other's developments and to articulate 3D mapping needs to industry, academia and standardization organisations and initiatives like OGC and INSPIRE

\section{REFERENCES}

Anguelov, d. C. Dulong, D. Filip, C. Frueh, S. Lafon, R. Lyon, A. Ogale, L. Vincent, J. Weaver. (2010) Google Street View : Capturing the World at Street Level. Computer 43 (6), 32-38, 2010.

Commandeur T (2012). Footprint decomposition combined with point cloud segmentation for producing valid 3D models. MSc Geomatics, GIS technology group, Delft Univer-sity of Technology, the Netherlands.

El-Sheimy, N. (1996) A Mobile Multi-Sensor System for GIS Applications in Urban Centers. International Archives of Photogrammetry, Remote Sensing and Spatial Information Sciences Vol. 31-B2, pp. 95-100, 1996.

Esri, (2016), I3S specifications, https://github.com/Esri/i3s-spec

Gandolfi, M. Barbarella, E. Ronci, A. Burchi. (2008) Close photogrammetry and laser scanning using a mobile mapping 
system for the high detailed survey of a high density area. International Archives of Photogrammetry, Remote Sensing and Spatial Information Sciences Vol. 35-Part B5, pp. 909-914

geo.admin.ch. (2016) The federal geoportal. http://www.geo.admin.ch/internet/geoportal/en/home.html, visited April 2016.

Geiger, A., P. Lenz, R. Urtasun (2012) Are we ready for Autonomous Driving? The KITTI Vision Benchmark Suite. In : Computer Vision and Pattern Recognition (CVPR), 2012.

Grejner-Brzezinska D.A., Positioning Accuracy of the GPSVan. (1996) In : Proceedings of the 52nd Annual Meeting of The Institute of Navigation, pp. 657-665, 1996.

Gontran, H. J. Skaloud, P.-Y. Guilleron (2007) A mobile mapping system for road data capture via a single camera. Advances in mobile mapping technology, C. Tao and D. Li (Eds). Taylor \& Francis Group, London, 43-50.

Goulette, F., F. Nashashibi, I. Abuhadrous, S. Ammoun, C. Laurgeau (2006) An Integrated On-Board Laser Range Sensing System for On-the-Way City and Road Modelling. International Archives of Photogrammetry, Remote Sensing and Spatial Information Sciences Vol. 36-1, 2006.

Kukko, A., C.-O. Andrei, V.-M. Salminen, H. Kaartinen, Y.i Chen, P. Rönnholm, H. Hyyppä, J. Hyyppä, R. Chen, H. Haggrén, I. Kosonen, K. Čapek (2007) Road environment mapping system of the Finnish Geodetic Institute-FGI Roamer. International Archives of Photogrammetry, Remote Sensing and Spatial Information Sciences 39, 241-247, 2007.

Oude Elberink, S., J. Stoter, H. Ledoux, T. Commandeur (2013). Generation and Dissem-ination of a National Virtual 3D City and Landscape Model for the Netherlands, Photogrammetric Engineering \& Remote Sensing, 79(2):147-158.

Oude Elberink, S.J. and G. Vosselman (2009a). 3D information extraction from laser point clouds covering complex road junctions. The Photogrammetric Record. 24(125):23-36.

Oude Elberink, S.J., G. Vosselman (2009b). Building reconstruction by target based graph matching on incomplete laser data: analysis and limitations. Sensors 9(8):6101-6118.

Paparoditis, N. J.-P. Papelard, B. Cannelle, A. Devaux, B. Soheilian, N. David, E. Houzay. (2012) Stereopolis II: A multipurpose and multi-sensor 3D mobile mapping system for street visualisation and 3D metrology. Revue Française de Photogrammétrie et de Télédétection 200: 69-79, October 2012.

Schmassmann, E. R. Bovier. (2010) Topografisches Landschaftsmodell TLM: swissTLM ${ }^{3 \mathrm{D}}$. Geomatik Schweiz Vol. 9, pp. 407-409, 2010

Stoter, J.E., Carsten Roensdorf, Rollo Home, David Capstick, Andre Streilein, Tobias Kellenberger, Eric Bayers, Paul Kane, Josef Dorsch, Piotr Wozniak, Gunnar Lysell, Thomas Lithen, Benedicte Bucher, Nicolas Paparoditis and Risto Ilves. (2014) 3D modelling with national coverage bridging the gap between research and practice. 9th International 3DGeoInfo 2014

Swisstopo (2016) Landscape Models.

http://www.swisstopo.admin.ch/internet/swisstopo/en/home/pro ducts/landscape.html, visited April 2016.
Stoter, J.E., Ploeger, H., van Oosterom, P. (2012) 3D cadastre in the Netherlands: Developments and international applicability In: Computers, Environment and Urban Systems, Volume 36, 2012, 12 p.

Van den Brink L., J. Stoter, and S. Zlatanova (2013a). Establishing a national standard for 3D topographic data compliant to CityGML, International Journal of Geographical In-formation Science, 27(1):92-113.

Van den Brink L., J.E. Stoter, and S. Zlatanova (2013b). UMLbased approach to develop-ing a CityGML application domain extension, Transactions in GIS 12/2013; 17(6). DOI:10.1111/tgis.12026 